\title{
Suppression of Normal Human Erythropoiesis by Gamma Interferon In Vitro Role of Monocytes and T Lymphocytes
}

\author{
Steven W. Mamus, Sherri Beck-Schroeder, and Esmail D. Zanjani \\ Department of Medicine, Division of Hematology, Veterans Administration Medical Center, \\ University of Minnesota School of Medicine, Minneapolis, Minnesota 55455
}

\begin{abstract}
Interferons (IFN) have been shown to suppress the proliferation of human erythroid progenitors (erythroid burst-forming units [BFU-E] and colony-forming units [CFU-E]) in vitro. To examine the mechanism(s) underlying this inhibitory activity, the effect of different doses $(50-10,000 \mathrm{U})$ of a highly purified preparation of recombinant DNA produced human $\gamma$-IFN on erythroid colony formation by normal human bone marrow BFU-E and CFU-E in the presence and absence of monocytes and/or $T$ lymphocytes was studied. The addition of $\gamma$-IFN to whole marrow caused suppression of BFU-E (6-65\%) and CFU-E (31-79\%) in a dose-dependent fashion. This inhibition occurred both with the direct addition of $\boldsymbol{\gamma}$-IFN to the culture plates as well as by the preincubation of marrow cells with $\gamma$-IFN followed by the washing of the cells; at the highest concentration of $\gamma$-IFN (10,000 U), near-maximal inhibition of colony formation occurred with as little as 15 min of preexposure (BFUE, 50\%; CFU-E, 81\%). Removal of monocytes and/or $T$ lymphocytes before the addition of $\boldsymbol{\gamma}$-IFN significantly reduced the inhibitory effects of this lymphokine (BFU-E, -1 to $38 \%$; CFU-E, -8 to 67\%). Co-culture of purified autologous monocytes or $T$ cells preexposed to $\gamma$-IFN with monocyte and $T$ cell-depleted marrow cells resulted in highly significant inhibition of erythroid colony formation even when these treated cells comprised $<1 \%$ of the total nucleated cell populations in culture. The inhibitory action of $\boldsymbol{\gamma}$-IFN was not prevented or reversed by erythropoietin. These results demonstrate that the inhibitory effects of $\boldsymbol{\gamma}$-IFN on erythropoiesis are mediated to a significant degree through accessory cell populations, and suggest that $\boldsymbol{\gamma}$-IFN may represent a useful tool in the study of the role of immunocompetent cells in the regulation of erythropoiesis in vitro.
\end{abstract}

\section{Introduction}

Interferons (IFN) ${ }^{1}$ are biologically active molecules that are produced by nucleated cells in response to viral infections as

This work has been presented in part at the meeting of the International Society for Experimental Hematology at Atlanta, GA in August 1984 and has appeared as an abstract (1984. Exp. Hematol. 12:366).

Received for publication 20 August 1984 and in revised form 26 November 1984.

1. Abbreviations used in this paper: BFU-E, erythroid burst-forming unit; BMC, bone marrow cell; BPA, burst-promoting activity; CFU-E, colony-forming unit; Ep, erythropoietin; FCS, fetal calf serum; IFN, interferon; IMDM, Iscove's modified Dulbecco's medium; MO, monocyte-macrophage; SRBC, sheep erythrocyte.

The Journal of Clinical Investigation, Inc.

Volume 75, May 1985, 1496-1503 well as to a number of other stimuli (1). As a class of molecules, IFN are capable of a diverse range of functions both in vivo and in vitro. Although initially recognized and defined by their antiviral properties (2-4), it has become obvious that this group of glycoproteins may play a significant role in cellular differentiation (5), proliferation $(6,7)$, and immunoregulation $(8,9)$.

IFN have been shown to suppress the proliferation and/or differentiation of normal human bone marrow pluripotent (CFU-GEMM) (10), granulocyte-macrophage (granulocytemacrophage colony-forming units [CFU-GM]) (11), and erythroid $(7,12)$ progenitors (erythroid burst-forming units [BFUE] and colony-forming units [CFU-E]) in vitro. In vitro suppression of murine bone marrow megakaryocyte colonyforming cells has also been reported (13). More recently, the possibility that IFN may play a role in the pathogenesis of aplastic anemia has been suggested $(14,15)$. In support of this hypothesis, it has been demonstrated that (a) IFN was a mediator of the in vitro suppression of hematopoiesis by cells from patients with aplastic anemia (15), and (b) IFN was present in higher than normal concentrations in bone marrow of seven of seven aplastic anemia patients (16). Moreover, the development of red cell aplasia, responsive to immunotherapy, in a patient with well-differentiated lymphocytic lymphoma after treatment with IFN has been documented (17). The mechanism(s) underlying the suppressive effect of IFN on hematopoiesis is not known. In this regard, it is generally accepted that immunocompetent cells, principally $T$ cells and monocyte-macrophages (MO) play an important regulatory role in hematopoietic progenitor cell activity (18-21). Furthermore, increasing evidence points to IFN as a potent modulator of a variety of cell-mediated immune responses $(22,23)$; IFN have been shown to augment the cytotoxic activities of MO and natural killer cells $(8,24)$. The present study was designed to examine the role of $\mathrm{T}$ cells and MO in the mediation of the suppressive effect of a highly purified preparation of recombinant DNA-derived human $\gamma$-IFN on normal human bone marrow BFU-E and CFU-E in vitro. The results demonstrate that $(a) \gamma$-IFN is a potent suppressor of human erythropoiesis in vitro, $(b)$ this inhibitory activity, which is not prevented/reversed by erythropoietin (Ep), is exercised more at the level of CFU-E than BFU-E, and more importantly, (c) $\mathrm{T}$ cells and MO play an important part in the mediation of this effect.

\section{Methods}

Cells and cell separation procedures. All bone marrow aspirations were performed at the posterior iliac crest. Heparinized (preservative-free) bone marrow and peripheral blood were obtained from normal healthy adult donors subsequent to obtaining informed consent. Bone marrow cells (BMC) and blood mononuclear cells were isolated by Ficoll- 
Hypaque density-gradient centrifugation (1.077 sp gr). When required, BMC were depleted of MO by adherence to plastic surfaces. $15 \mathrm{ml}$ of BMC $\left(5 \times 10^{6}\right.$ cells $\left./ \mathrm{ml}\right)$, suspended in Iscove's modified Dulbecco's medium (IMDM) with $20 \%$ fetal calf serum (FCS) was placed in 75 $\mathrm{cm}^{2}$ plastic tissue culture flasks and allowed to adhere for $2 \mathrm{~h}$ at $37^{\circ} \mathrm{C}$ in a humidified atmosphere of $5 \% \mathrm{CO}_{2}$ in air. Nonadherent cells (BMC-MO) were collected by gentle agitation of the flasks and slow removal of the supernatant. The mixture was spun at $1,400 \mathrm{rpm}$ for $10 \mathrm{~min}$, washed once in IMDM and resuspended in IMDM at desired concentrations. Adherent cells for use in co-culture studies were removed by either gentle scraping with a rubber policeman or by exposure to EDTA (2\% in phosphate-buffered saline) for $15 \mathrm{~min}$ followed by washing three times and resuspension in IMDM at desired concentrations. Removal of $\mathrm{T}$ lymphocytes from BMC-MO (BMC-MO-T) was achieved by double rosetting with sheep erythrocytes (SRBC); the second rosetting was performed overnight at $37^{\circ} \mathrm{C}$, $5 \% \mathrm{CO}_{2}$ in humidified air. These procedures resulted in complete removal of $\mathrm{MO}$ and $\mathrm{T}$ cells as determined by the use of monoclonal antibodies LeuM3 (Becton, Dickinson Monoclonal Center, Inc., Mountain View, CA), MO2 (Coulter Immunology, Hialeah, FL), and OKT3 (Ortho Diagnostic Systems, Inc., Raritan, NJ) (25-28). Autologous $T$ cells for co-culture experiments were obtained from PBMC-MO by single SRBC-rosetting and lysis of SRBC. Isolated T cells were on the average $95-97 \% \mathrm{SRBC}^{+}$and $\mathrm{OKT}^{+}$. Isolated MO populations were evaluated for purity by a nonspecific esterase staining reaction (29), which revealed $90-99 \%$ nonspecific esterase-positive cells. Each of these separation procedures also resulted in a significant loss of total bone marrow nucleated cells. The percentages of total marrow nucleated cells recovered were: BM-MO, 49.9 $\pm 5.0 \%$; BM-T, $28.7 \pm 3.6 \%$; BM-MO-T, $23.4 \pm 3.2 \%$.

Clonal assays. Erythroid progenitors (BFU-E, CFU-E) were assayed in a plasma clot culture system as described (21). Bone marrow cells (BMC, 3-4 $310^{5}$ cells $/ 1.1 \mathrm{ml}$; BMC-MO, $4 \times 10^{5}$ cells $/ 1.1 \mathrm{ml}$; BMC-T, $2 \times 10^{5}$ cells $/ 1.1 \mathrm{ml}$; BMC-MO-T, $2 \times 10^{5}$ cells $\left./ 1.1 \mathrm{ml}\right)$ were cultured in quadruplicate wells $(0.1 \mathrm{ml} /$ well) with $\mathrm{Ep}(0.5 \mathrm{IU} / 1.1$ $\mathrm{ml}$, unless otherwise specified) in the presence or absence of different concentrations of $\gamma$-IFN and/or autologous MO/T. The plates were incubated at $37^{\circ} \mathrm{C}$ in a humidified atmosphere of $5 \% \mathrm{CO}_{2}$ in air for 7 $\mathrm{d}$ (CFU-E) and $15 \mathrm{~d}$ (BFU-E). The clots were then removed, placed on glass slides, fixed with gluteraldehyde and stained with benzidine. Ep (CAT-1, 1972 IU/mg protein) used in these studies was generously supplied by the Blood Resources Division of the National Heart, Lung and Blood Institute of the National Institutes of Health.

Preincubation studies. The effect of $\gamma$-IFN on erythroid colony formation was examined in the following way. (a) Varying doses of $\gamma$ IFN (50-20,000 U/1.1 ml) were added to the different cell preparations at the start of incubation and the mixture was cultured for 7 and 15 $\mathrm{d}$ as described. (b) The exact numbers of bone marrow target cells to be cultured were preincubated with either control medium (IMDM, $10 \%$ FCS) or medium containing different doses of $\gamma$-IFN $(800-20,000$ $\mathrm{U} / \mathrm{ml}$ ) at $37^{\circ} \mathrm{C}$ in a water bath with gentle shaking for $15-60 \mathrm{~min}$, washed one to four times (IMDM, 10\% FCS, 1,400 rpm for $10 \mathrm{~min}$ ), resuspended in complete culture medium and cultured as above. (c) Autologous T cells or MO were preincubated with either medium alone (IMDM, $10 \%$ FCS) or medium containing varying doses of $\gamma$ IFN $(800-20,000 \mathrm{U} / \mathrm{ml})$ at $37^{\circ} \mathrm{C}$ in a water bath with gentle shaking for 15-60 min, washed one to four times (IMDM, 10\% FCS, 1,400 $\mathrm{rpm}$ for $10 \mathrm{~min}$ ), resuspended in IMDM at desired concentrations and co-cultured with the different bone marrow cell preparations for 7 and $15 \mathrm{~d}$. The numbers of $\mathrm{MO}$ or $\mathrm{T}$ cells used in co-culture studies comprised $0.24-8 \%$ of the total nucleated cell populations in culture.

Human interferon. The two highly purified recombinant DNAderived preparations of human $\gamma$-IFN (Biogen, Inc., Cambridge, MA) used in these studies (93-97\% pure) had the following characteristics: activity, $11.3 \times 10^{7} \mathrm{U} / \mathrm{ml}$ (National Institutes of Health reference units); sp act, $7 \times 10^{7} \mathrm{U} / \mathrm{mg}$; pyrogens, $1.3 \mathrm{ng} / \mathrm{ml}$; penicillin, $\leq 7.8 \mathrm{ng} /$ $\mathrm{ml}$; and Escherichia coli protein, $60 \mathrm{ng} / \mathrm{ml}$. All dilutions were carried out in IMDM.

\section{Results}

The addition of $\gamma$-IFN to BMC resulted in significant inhibition of erythroid colony formation in a dose-dependent fashion (Fig. 1). This was evident not only by a significant decrease in the numbers of colonies formed, but also by the reduced size of individual colonies. Although the degree of inhibition was dependent on the dose of $\gamma$-IFN used, generally two plateaus were noted. The level of suppression was unchanged with doses between 50 and $800 \mathrm{U} / 1.1 \mathrm{ml}$, peaked, and plateaued again at 1,600-10,000 U/1.1 $\mathrm{ml}$ range (Fig. 1). Overall, the effect was more pronounced on CFU-E than BFU-E at lower doses of $\gamma$-IFN. However, a similar degree of suppression was seen when higher doses were employed (Fig. 1). The inhibitory effect of $\gamma$-IFN was completely abolished by the use of a monospecific anti- $\gamma$-IFN antibody (data not shown). In the studies reported here, except those described in Table I, the cultures were established in the presence of $0.5 \mathrm{IU}$ of $\mathrm{Ep} / 1.1$ $\mathrm{ml}$. This dose of Ep is used because in our hands, nearmaximal stimulation of CFU-E-derived colony formation occurs at this dose and the effect on BFU-E falls within the linear portion of the dose-response curve; we frequently observe a plateau for BFU-E with doses of $\mathrm{Ep} \geq 1 \mathrm{IU} / 1.1 \mathrm{ml}$. In addition, the suppressive effect of $\gamma$-IFN on both CFU-E and BFU-E is not affected by the dose of Ep employed (Table I).

Results presented in Table I demonstrate that the inhibition of erythroid colony formation by the direct addition of $\gamma$-IFN to the culture was independent of the dose of Ep used; concentrations of Ep between 0.5 and $5 \mathrm{IU} / 1.1 \mathrm{ml}$ failed to prevent the suppression of CFU-E and/or BFU-E activity by $\gamma$-IFN. This was true both when the different Ep doses were added to culture at the start of incubation (Table I), and when BMC were preincubated with up to $10 \mathrm{IU}$ of EP for $1 \mathrm{~h}$ before the addition of $\gamma$-IFN (data not shown). In these studies, cells were exposed to Ep $(0.5-10 \mathrm{IU} / \mathrm{ml})$ for $1 \mathrm{~h}$, washed, and replated in the presence of $0.5-10 \mathrm{IU}$ of Ep/1.1 ml.

The effect of different concentrations of $\gamma$-IFN on erythroid colony formation by $\mathrm{BMC}-\mathrm{MO}\left(0 \% \mathrm{LeuM}^{+}, 0 \% \mathrm{MO}^{+}\right.$, $0.5 \%$ nonspecific esterase ${ }^{+}, 3-6 \% \mathrm{OKT}^{+}, 3-6 \% \mathrm{SRBC}^{+}$) is shown in Fig. 2. In these, as well as studies presented in Figs. 3 and 4, no attempt was made to present the results in terms of colonies produced by a given number of non-MO and/or $T$ cells. As a result, the numbers for both classes of progenitors

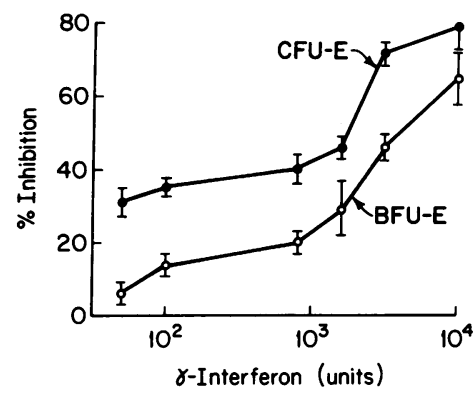

Figure 1. Effect of $\gamma$-IFN on erythroid colony formation by intact normal human bone marrow cells in vitro. Each data point on this linear-log plot represents mean \pm 1 SEM of results from eight separate studies each involving a different normal marrow donor. Percentage of inhibition was calculated by reference to values obtained in control cultures: CFU-E, 305 \pm 25 ; BFUE, $201 \pm 39$ colonies $/ 10^{5}$ cells. When compared to control cultures, the effect on CFU-E was statistically significant $(P<0.05)$ beginning at $\gamma$-IFN dose of $50 \mathrm{U} / \mathrm{ml}$; statistically significant $(P<0.05)$ inhibition of BFU-E was first detected at the $3,200 \mathrm{U} / \mathrm{ml}$ dose. 
Table I. Effect of Increasing Concentrations of Ep on the Inhibitory Action of $\gamma-I F N$ on Erythroid Colony Formation by Normal Human BMC in Vitro*

\begin{tabular}{|c|c|c|c|c|}
\hline Additions to cultures & BFU-E & CFU-E & BFU-E & CFU-E \\
\hline & Colonies $/ 10^{s}$ cells $\ddagger$ & Colonies $/ 10^{5}$ cells $\ddagger$ & \%o inhibition & \% inhibition \\
\hline None & 0 & 0 & - & - \\
\hline 0.5 IU Ep§ & $76 \pm 10$ & $186 \pm 11$ & - & - \\
\hline 0.5 IU Ep§ $+3,200$ U IFN & $36 \pm 4$ & $28 \pm 3$ & 53 & 85 \\
\hline $0.5 \mathrm{IU} \mathrm{Ep} \S+10,000 \mathrm{U}$ IFN & $26 \pm 5$ & $35 \pm 6$ & 66 & 81 \\
\hline $1.0 \mathrm{IU} \mathrm{Ep}$ & $108 \pm 18$ & $264 \pm 29$ & - & - \\
\hline 1.0 IU Ep $+3,200$ U IFN & $50 \pm 7$ & $54 \pm 9$ & 54 & 80 \\
\hline 1.0 IU Ep $+10,000$ U IFN & $38 \pm 5$ & $35 \pm 6$ & 65 & 87 \\
\hline $2.0 \mathrm{IU} \mathrm{Ep}$ & $139 \pm 14$ & $225 \pm 23$ & - & - \\
\hline 2.0 IU Ep $+3,200$ U IFN & $83 \pm 4$ & $71 \pm 16$ & 40 & 68 \\
\hline 2.0 IU Ep $+10,000$ U IFN & $67 \pm 13$ & $79 \pm 24$ & 52 & 65 \\
\hline $5.0 \mathrm{IU} \mathrm{Ep}$ & $160 \pm 6$ & $263 \pm 17$ & - & - \\
\hline 5.0 IU Ep $+3,200$ U IFN & $62 \pm 5$ & $48 \pm 21$ & 61 & 62 \\
\hline 5.0 IU Ep $+10,000$ U IFN & $56 \pm 4$ & $28 \pm 6$ & 65 & 89 \\
\hline
\end{tabular}

* Ep and $\gamma$-IFN were added at the start of culture. See text for details. $\ddagger$ Each value represents mean \pm 1 SEM of results from two separate studies each involving a different normal donor. § Ep (CAT-1) used in these studies was provided by the Blood Resources Division, National Heart, Lung and Blood Institute, National Institutes of Health; $0.5 \mathrm{IU} \mathrm{Ep} / 1.1 \mathrm{ml}$ of culture was used.

are higher than those given in Fig. 1 and Table I, which simply reflects the concentration effects of the depletion procedures employed. It is interesting to note, however, that the relative increase in BFU-E density when both $\mathrm{T}$ cells and MO were removed was not as high as when the marrow was depleted of $T$ cells alone (BMC - T, $650 \pm 89$ vs. BMC-MO-T, $375 \pm 65$ BFU-E $/ 10^{5}$ cells). Similarly, removal of MO alone did not result in a significant increase in detectable BFU-E density (BMC, $201 \pm 39$ vs. BMC-MO, $200 \pm 35 \mathrm{BFU}-\mathrm{E} / 10^{5}$ cells). We interpret these results to indicate that adherent cells play a significant helper function in bone marrow BFU-E development in vitro. We did not feel it necessary, however, to perform these studies in the presence of added burst-promoting activity (BPA) because $\gamma$-IFN-mediated inhibition of erythropoiesis occurred even when intact BMC were used. Moreover, $\gamma$-IFN

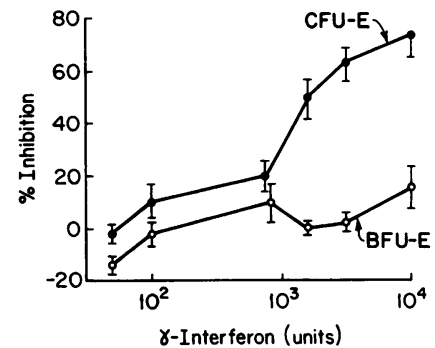

Figure 2. Effect of $\gamma$-IFN on erythroid colony formation by monocyte-depleted normal human bone marrow cells in vitro. Each data point on this linear-log plot represents results from six separate studies each involving a different normal marrow donor. Percentage of inhibition was calculated by reference to values obtained in control cultures: CFU-E, $271 \pm 33$; BFU-E, $200 \pm 35$ colonies $/ 10^{5}$ cells. When compared to control cultures, the effect on CFU-E became statistically significant at $\gamma$-IFN dose of $1,600 \mathrm{U} / \mathrm{ml}(P<0.05)$; the effect on BFU-E did not reach statistically significant levels at any dose of $\boldsymbol{\gamma}$-IFN. was previously shown to inhibit erythroid colony development in cultures supplemented with exogenous BPA (12).

The results presented in Fig. 2 show that only modest inhibition of BFU-E occurred when $\gamma$-IFN was added directly to BMC-MO. Moreover, the suppressive effect of $\gamma$-IFN on the more mature CFU-E, although significant, was decreased when compared to BMC (4-8\% LeuM3 ${ }^{+}, 2-5 \% \mathrm{MO}^{+}, 4-11 \%$ $\mathrm{OKT}^{+}, 4-11 \% \mathrm{SRBC}^{+}$). When $\gamma$-IFN was added directly to bone marrow cells depleted of T cells (BMC-T) $\left(0 \% \mathrm{OKT}^{+}\right.$, $0 \% \mathrm{SRBC}^{+}, 2-5 \% \mathrm{LeuM}^{+}, 2-8 \% \mathrm{MO}^{+}$), again less inhibition of either CFU-E or BFU-E occurred over the dose range of 50-3,200 U (Fig. 3) when compared to $\gamma$-IFN effect on whole marrow. When $\gamma$-IFN was added to bone marrow cells depleted of both $\mathrm{T}$ cells as well as monocytes $\left(0 \% \mathrm{OKT}^{+}, 0 \% \mathrm{SRBC}^{+}\right.$,

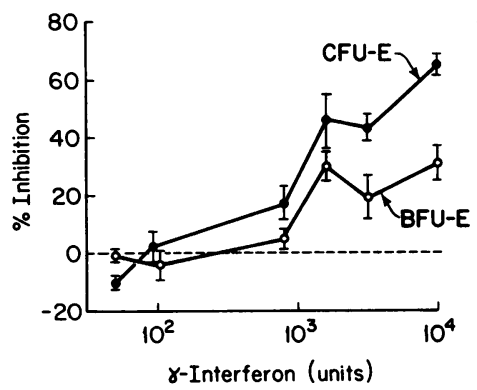

Figure 3. Effect of $\gamma$-IFN on erythroid colony formation by $T$ cell-depleted normal human bone marrow cells in vitro. Each data point on this linear-log plot represents mean \pm 1 SEM of results from three separate studies each involving a different normal marrow donor. Percentage of inhibition was calculated by reference to values obtained in control cultures: CFU-E, $821 \pm 79$; BFUE, $650 \pm 89$ colonies $/ 10^{5}$ cells. When compared to control cultures, the effect of CFU-E was statistically significant $(P<0.05)$ beginning at $\gamma$-IFN dose of $1,600 \mathrm{U} / \mathrm{ml}$; the effect on BFU-E was not statistically significant. 


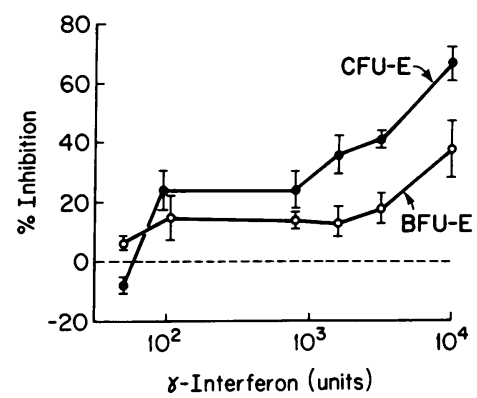

Figure 4. Effect of $\gamma$-IFN on erythroid colony formation by $\mathrm{T}$ cell and monocyte-depleted normal human bone marrow cells in vitro. Each data point on this linear-log plot represents results from four separate studies each involving a different normal marrow donor. Percentage of inhibition was calculated by reference to values obtained in control cultures: CFU-E, 613 \pm 76 ; BFU-E, $375 \pm 65$ colonies $/ 10^{5}$ cells. When compared to control cultures, statistically significant $(P<0.05)$ inhibition of CFU-E was seen starting with $1,600 \mathrm{U} / \mathrm{ml}$ of $\gamma$-IFN; the effect on BFU-E was not statistically significant.

$0 \% \mathrm{LeuM}^{+}, 0 \% \mathrm{MO}^{+}$), only modest inhibition of BFU-E was seen ( $31 \%$ with $10,000 \mathrm{U}$ of $\gamma$-IFN) and the inhibitory effect on CFU-E was also moderated (Fig. 4). To determine whether the suppression of erythropoiesis by $\gamma$-IFN in vitro requires the continuous presence of the lymphokine, we performed preincubation studies where BMC were exposed to varying doses of $\gamma$-IFN $(1,600,3,200$, or $10,000 \mathrm{U})$ for 15,30 , or $60 \mathrm{~min}$, washed, and then cultured in plasma clots in the presence of Ep alone. The results of these studies are shown in Table II and indicate that the $\gamma$-IFN-mediated suppression of CFU-E and BFU-E is both dose and time dependent. Thus at a dose of $10,000 \mathrm{U}$ of $\gamma$-IFN, maximal inhibition of CFU$\mathrm{E}$ and BFU-E occurred with as little as $15 \mathrm{~min}$ of preincubation. As seen in Table III, preincubation with $10,000 \mathrm{U}$ of $\gamma$-IFN for $15 \mathrm{~min}$, washing the cells, followed by the direct addition to culture of up to $1,600 \mathrm{U}$ of $\gamma$-IFN resulted in no further inhibition of erythroid colony formation. These results suggest that the inhibitory effect of $\gamma$-IFN on CFU-E and BFU-E can result from very brief exposure to $\gamma$-IFN, that $\gamma$-IFN mediated suppression of erythroid colony formation is both dose and time dependent, and that at the doses utilized, near-maximal inhibitory effect can be achieved by preincubation.

To further delineate the role of immunocompetent cells in
Table III. Effect of IFN on Erythroid Colony Formation by Normal Human BMC Preexposed to IFN*

\begin{tabular}{|c|c|c|}
\hline Culture conditions & CFU-E $/ 10^{5}$ cells $\ddagger$ & \% inhibition \\
\hline $\mathbf{B M}+\mathbf{E p}$ & $293 \pm 60$ & - \\
\hline \multicolumn{3}{|l|}{$\mathrm{BM}+\mathrm{Ep}+10,000 \mathrm{U}$} \\
\hline IFN§ & $61 \pm 11$ & 79 \\
\hline BM (preincubated) + Ep" & $262 \pm 8$ & - \\
\hline \multicolumn{3}{|l|}{ BM (preincubated with } \\
\hline 10,00 U IFN) + Ep & $73 \pm 8$ & 72 \\
\hline \multicolumn{3}{|l|}{ BM (preincubated with } \\
\hline \multicolumn{3}{|l|}{10,000 U IFN) + Ep } \\
\hline+800 U IFN & $41 \pm 3$ & 84 \\
\hline \multicolumn{3}{|l|}{ BM (preincubated with } \\
\hline \multicolumn{3}{|l|}{10,000 U IFN) + Ep } \\
\hline+1600 U IFN & $44 \pm 4$ & 83 \\
\hline
\end{tabular}

* BMC were incubated with IFN or medium alone for $1 \mathrm{~h}$, washed, and cultured in plasma clot in the presence of $0.5 \mathrm{IU}$ Ep with and without IFN.

$\ddagger$ Each value represents mean \pm 1 SEM of results from two separate studies each involving a separate normal donor.

$\S \gamma$-IFN.

"Erythropoietin.

the mediation of $\gamma$-IFN effect on CFU-E and BFU-E, autologous $\mathrm{T}$ cells and MO $\left(1-16 \times 10^{3}\right.$ cells $\left./ 1.1 \mathrm{ml}\right)$ were preincubated with either control medium or $\gamma$-IFN $(3,200-20,000 \mathrm{U})$, washed, and co-cultured with BMC-MO-T in the presence of Ep alone. Results presented in Tables IV and V demonstrate that the addition of as few as 1,000 $\gamma$-IFN treated T cells (Table IV) or MO (Table V) (comprising $0.24 \%$ of total nucleated cells present in culture) to autologous BMC-MO-T resulted in near-maximal inhibition of CFU-E-derived colony formation. The effect on BFU-E-derived colony formation, although significant, was less pronounced.

\section{Discussion}

The results presented here demonstrate that human $\gamma$-IFN is a potent inhibitor of human erythropoiesis in vitro. Thus the

Table II. Effect of Preexposure of Normal Human BMC to $\gamma$-IFN on Erythroid Colony Formation in Response to Ep In Vitro*

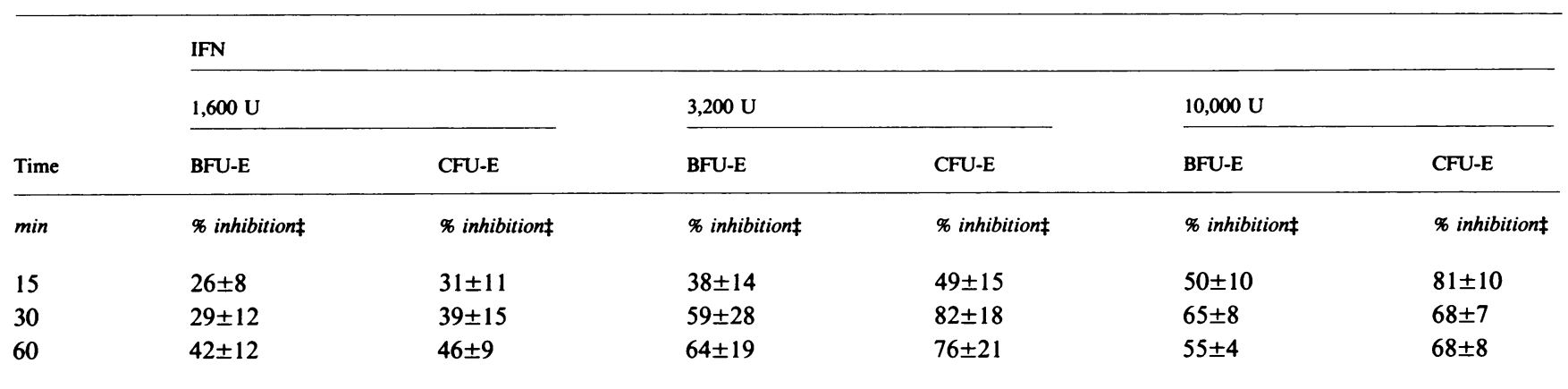

* Cells were incubated with the indicated doses of $\gamma$-IFN for 15-60 min, washed, and cultured in the presence of 0.5 IU Ep (see text for details.) $¥$ Calculated from mean colony counts obtained in three separate studies each involving a different normal marrow donor. Mean control (incubated without IFN) colony counts used to calculate the \% inhibitions (mean \pm 1 SEM) were: BFU-E, $140 \pm 15$ colonies $/ 10^{5}$ cells and CFU-E, $231 \pm 26$ colonies $/ 10^{5}$ cells. 
Table IV. Effect of Autologous T Cells Preincubated with $\gamma$-IFN on Erythroid Colony Formation by

$T$ - and Monocyte-depleted Normal Human BMC in Vitro

\begin{tabular}{|c|c|c|}
\hline Additions to cultures & BFU-E & CFU-E \\
\hline & Colonies $/ 10^{5}$ cells ${ }^{*}$ & Colonies $/ 10^{5}$ cells* \\
\hline None & $\mathbf{0}$ & 0 \\
\hline Epł & $292 \pm 14$ & $600 \pm 55$ \\
\hline \multicolumn{3}{|l|}{$\mathrm{Ep} \ddagger+\left(10^{3} \mathrm{~T}\right.$} \\
\hline+ medium $) \S$ & $299 \pm 40$ & $389 \pm 104$ \\
\hline \multicolumn{3}{|l|}{ Ep $\neq+\left(10^{3} T+3,200\right.$} \\
\hline U IFN) & $298 \pm 45(0 \%)^{11}$ & $96 \pm 22(75 \%)$ \\
\hline \multicolumn{3}{|c|}{$\mathrm{Ep} \ddagger+\left(10^{3} T+10,000\right.$} \\
\hline U IFN) & $144 \pm 20(52 \%)$ & $22 \pm 5 \quad(95 \%)$ \\
\hline \multicolumn{3}{|c|}{$\mathrm{Ep} \ddagger+\left(10^{3} T+20,000\right.$} \\
\hline U IFN) & $176 \pm 22(41 \%)$ & $16 \pm 5 \quad(96 \%)$ \\
\hline \multicolumn{3}{|l|}{ Ep $\ddagger+\left(8 \times 10^{3} \mathrm{~T}\right.$} \\
\hline+ medium) & $260 \pm 16$ & $513 \pm 77$ \\
\hline \multicolumn{3}{|l|}{$\mathrm{Ep} \ddagger+\left(8 \times 10^{3} \mathrm{~T}\right.$} \\
\hline$+3,200$ U IFN) & $250 \pm 30(4 \%)$ & $136 \pm 11(74 \%)$ \\
\hline \multicolumn{3}{|l|}{ Ep $\ddagger\left(8 \times 10^{3} \mathrm{~T}\right.$} \\
\hline$+10,000$ U IFN) & $206 \pm 48(21 \%)$ & $86 \pm 6 \quad(84 \%)$ \\
\hline \multicolumn{3}{|l|}{$\mathrm{Ep} \ddagger+\left(8 \times 10^{3} \mathrm{~T}\right.$} \\
\hline$+20,000$ U (FN) & $185 \pm 23(29 \%)$ & $88 \pm 11(83 \%)$ \\
\hline \multicolumn{3}{|l|}{ Ep $\neq+\left(16 \times 10^{3} \mathrm{~T}\right.$} \\
\hline + medium) & $321 \pm 39$ & $559 \pm 39$ \\
\hline \multicolumn{3}{|l|}{ Ep $\ddagger\left(16 \times 10^{3} \mathrm{~T}\right.$} \\
\hline$+3,200$ U IFN) & $378 \pm 23(-18 \%)$ & $347 \pm 49(38 \%)$ \\
\hline \multicolumn{3}{|l|}{ Ep $\ddagger\left(16 \times 10^{3} \mathrm{~T}\right.$} \\
\hline$+10,000$ U IFN) & $142 \pm 33(56 \%)$ & $99 \pm 22(83 \%)$ \\
\hline \multicolumn{3}{|l|}{ Ep $\ddagger\left(16 \times 10^{3} \mathrm{~T}\right.$} \\
\hline$+20,000$ U IFN) & $144 \pm 23(56 \%)$ & $100 \pm 11(82 \%)$ \\
\hline
\end{tabular}

* Mean \pm 1 SEM of results from quadruplicate cultures. $¥$ See legend to Table I; $0.5 \mathrm{IU} \mathrm{Ep} / 1.1 \mathrm{ml}$ was used.

$\S \mathrm{T}$ cells were incubated with medium or $\gamma$-IFN for $1 \mathrm{~h}$, washed, and co-cultured with marrow cells.

"Values in parentheses indicate \% inhibition by direct comparison to medium controls for each $\mathrm{T}$ cell concentration used.

addition of $\gamma$-IFN to normal human BMC resulted in highly significant suppression of erythroid progenitor activity in vitro. This activity, which was completely prevented by anti- $\gamma$-IFN, was not mediated through the alteration of the activity and/or target-recognition ability of $\mathrm{Ep}$, inasmuch as the addition of large concentrations of Ep to the cultures or preexposure of marrow cells to Ep failed to prevent/reverse the $\gamma$-IFN-mediated suppression of CFU-E and BFU-E. This is in accord with results reported by other investigators demonstrating the Epindependent nature of interferon effect on erythropoiesis in vitro $(30,31)$. It is of interest to note, however, that increasing the concentration of colony-stimulating factor has been reported to completely overcome the inhibitory effects of interferons on CFU-GM in the murine system (32).

These results also demonstrate that the inhibitory action of $\gamma$-IFN on erythropoiesis is mediated, at least in part, through MO and T cells; removal of these cells before the addition of $\gamma$-IFN significantly reduced the suppressive effect of $\gamma$-IFN. In
Table V. Effect of Autologous Monocytes Preincubated with $\gamma$-IFN on Erythroid Colony Formation by T- and Monocyte-depleted Normal Human BMC in Vitro

\begin{tabular}{|c|c|c|}
\hline Additions to cultures & BFU-E & CFU-E \\
\hline & Colonies $/ 10^{5}$ cells* & Colonies $110^{5}$ cells* \\
\hline None & 0 & 0 \\
\hline Epł & $292 \pm 14$ & $600 \pm 55$ \\
\hline \multicolumn{3}{|l|}{ Ep $\neq+\left(10^{3}\right.$ monocytes } \\
\hline+ medium $) \S$ & $307 \pm 34$ & $493 \pm 66$ \\
\hline \multicolumn{3}{|l|}{ Ep $\ddagger+\left(10^{3}\right.$ monocytes } \\
\hline$+3,200$ U IFN) & $353 \pm 46(-15 \%)^{11}$ & $277 \pm 66(44 \%)$ \\
\hline \multicolumn{3}{|l|}{ Ep $\ddagger+\left(10^{3}\right.$ monocytes } \\
\hline$+10,000$ U (FN) & $202 \pm 27(34 \%)$ & $97 \pm 17(80 \%)$ \\
\hline \multicolumn{3}{|l|}{ Ep $\ddagger+\left(10^{3}\right.$ monocytes } \\
\hline$+20,000$ U (FN) & $165 \pm 11(46 \%)$ & \\
\hline \multicolumn{3}{|c|}{ Ep $\ddagger+\left(8 \times 10^{3}\right.$ monocytes } \\
\hline+ medium) & $320 \pm 22$ & $504 \pm 72$ \\
\hline \multicolumn{3}{|c|}{ Ep $\neq+\left(8 \times 10^{3}\right.$ monocytes } \\
\hline$+3,200$ U IFN) & $377 \pm 25(-17 \%)$ & $301 \pm 39(40 \%)$ \\
\hline \multicolumn{3}{|c|}{ Ep $+\left(8 \times 10^{3}\right.$ monocytes } \\
\hline$+10,000$ U (FN) & $238 \pm 45(26 \%)$ & $106 \pm 6 \quad(79 \%)$ \\
\hline \multicolumn{3}{|c|}{ Ep $\ddagger+\left(8 \times 10^{3}\right.$ monocytes } \\
\hline$+20,000$ U (FN) & $172 \pm 15(46 \%)$ & $112 \pm 16(78 \%)$ \\
\hline \multicolumn{3}{|c|}{ Epł $+\left(16 \times 10^{3}\right.$ monocytes } \\
\hline+ medium) & $311 \pm 22$ & $514 \pm 33$ \\
\hline \multicolumn{3}{|c|}{ Epł $+\left(16 \times 10^{3}\right.$ monocytes } \\
\hline$+3,200$ U IFN) & $327 \pm 45(-5 \%)$ & $326 \pm 31(37 \%)$ \\
\hline \multicolumn{3}{|c|}{ Ep $\ddagger+\left(16 \times 10^{3}\right.$ monocytes } \\
\hline$+10,000$ U (FN) & $160 \pm 10(49 \%)$ & $105 \pm 11(80 \%)$ \\
\hline \multicolumn{3}{|c|}{ Ep $\ddagger+\left(16 \times 10^{3}\right.$ monocytes } \\
\hline$+20,000$ U (FN) & $121 \pm 6 \quad(61 \%)$ & $126 \pm 23(75 \%)$ \\
\hline
\end{tabular}

* Mean \pm 1 SEM of results from quadruplicate cultures. ‡ See legend to Table I; $0.5 \mathrm{IU}$ Ep/1.1 ml was used. $\S$ Monocytes were incubated with medium or $\gamma$-IFN for $1 \mathrm{~h}$, washed, and co-cultured with marrow cells.

"Values in parentheses indicate \% inhibition by direct comparison to medium controls for each monocyte concentration used.

this regard, $\gamma$-IFN appears to exert a differential effect on CFU-E and BFU-E. When utilizing BMC, CFU-E exhibited a greater sensitivity to $\gamma$-IFN, especially at lower doses, than BFU-E. This was also true when BMC-MO was cultured with $\gamma$-IFN; monocyte depletion resulted in the ablation of $\gamma$-IFNmediated suppression of BFU-E but not CFU-E. On the other hand, removal of $\mathrm{T}$ cells and/or $\mathrm{MO}$ and $\mathrm{T}$ cells before the addition of $\gamma$-IFN caused a significant decrease in both BFU$E$ and CFU-E suppression. It should be pointed out that the observed decreased sensitivity of erythroid progenitors to $\gamma$ IFN in the absence of MO and/or T cells was not due to individual marrow donor differences; on several occasions, intact and depleted marrows from the same donor were used. In all cases, significantly reduced inhibition was seen when MO and/or T cells were removed.

The finding that the removal of these immunocompetent cells causes a significant reduction in the $\gamma$-IFN-mediated suppression of human erythropoiesis in vitro suggests that the 
primary effect of $\gamma$-IFN may not be against BFU-E and CFU$E$ directly but rather through changes in the activity of accessory cell populations. However, a direct effect of $\gamma$-IFN on erythroid-committed progenitors or inhibition through activation of other non-monocyte, non-T accessory cells can not be ruled out. The bisigmoid nature of the CFU-E and BFU-E inhibition curves shown in Fig. 1, and the near-total elimination of the second (i.e., high dose) phase of the inhibitory effect by the removal of adherent cells (Fig. 2) suggest that $\gamma$-IFN more likely acts on two cell populations (erythroid progenitors and accessory cells). The findings reported here also show that, although the addition of either activated MO or activated $\mathrm{T}$ cells alone to BMC or BMC-MO-T can suppress erythropoiesis, removal of only one of these cell types markedly decreased $\gamma$-IFN-induced suppression of erythroid colony formation in vitro. This apparent paradox can best be explained by the possibility of involvement of a MO-T cell cooperation in the mediation of $\gamma$-IFN effect on erythropoiesis in vitro. In this regard, we have found that even when BMC rigorously depleted of MO and T cells were cultured, significant numbers of MO and $T$ cells were detected by day 7 of incubation. It is possible that these newly formed cells participate in the mediation of the overall effect of $\gamma$-IFN on erythropoiesis in vitro.

It is now well established that the proliferation and differentiation of erythroid progenitors in vitro is subject to regulatory influences of a number of accessory cell populations (18-21). Normal T cells and MO through production/release of soluble products, stimulate the growth of BFU-E and CFU-E in vitro $(18,19)$. By contrast, $T$ cells from some patients with blood dyscrasias, e.g., aplastic anemia (33), and MO from some patients with disseminated fungal infections (21) have been found to suppress the growth of autologous and heterologous BFU-E and CFU-E in vitro. Moreover, activation of normal $T$ cells by exposure to mitogenic factors (e.g., phytohemagglutinin, PHA) can render these cells inhibitory to hematopoietic progenitors (34). It is possible that the inhibitory effect of $\gamma$ IFN reported here is mediated through a similar "activation" of $\mathrm{T}$ cells and/or MO. When purified populations of donor $\mathrm{T}$ cells or MO were exposed to $\gamma$-IFN for $60 \mathrm{~min}$, washed, and co-cultured with autologous BMC, significant inhibition of erythroid colony formation occurred.

The mechanism(s) by which "activated" $T$ cells or MO affect erythropoiesis is not known. Activation of $T$ cells with phytohemagglutinin renders these cells inhibitory to erythropoiesis in vitro (34). A recent study suggests that the suppressive activity of lectin-treated $\mathrm{T}$ cells may be mediated through the production of $\gamma$-IFN by these cells (15). Activated T cells were found to produce an inhibitory supernatant with significant interferon activity (15). The suppressive activity of this supernatant was completely abrogated by treatment with antibody directed against $\gamma$-IFN (15). It is of interest to note, however, that similarly activated $T$ cells have been documented to produce factors capable of promoting the growth and differentiation of hematopoietic precursors in vitro $(18,35)$. The studies of Zoumbos et al. (15) showed that the production of interferon by activated $T$ cells peaked at days 3-5 of incubation and by day 7 were reduced to levels similar to those present in unstimulated cultures. This is in contrast to the finding that day 7 supernatants contain significant hematopoietic promoting factors (35). It appears, therefore, that the same stimulus can instruct these cells to assume both inhibitory and stimulatory functions with regard to hematopoiesis.

It is possible that the inhibitory effect of $\gamma$-IFN-treated cells on erythroid progenitors is mediated via soluble factors. However, in preliminary studies, we found that media conditioned by these cells for $1-3 \mathrm{~d}$ were devoid of inhibitory activity. Thus it is unlikely that the inhibitory effects of $\gamma$ IFN-treated cells are mediated through the production of interferons. Moreover, the effect can not be attributed to the carry-over by the treated cells of amounts of interferon sufficient to significantly inhibit erythropoiesis in vitro; we observed similar degree of inhibitory activity regardless of whether the dose of cells used in co-culture studies were obtained from small or very large pools of cells treated with the same dose of $\gamma$-IFN. In addition, repeated washing of the treated cells before co-culture with autologous BMC failed to alter their inhibitory effects on erythropoiesis. An alternative possibility is that the observed inhibition is not mediated by a secretory product, but rather is the end result of specific cellular activation and an antiproliferative effect mediated via direct cell-to-cell contact.

It is now well established that the interferon-induced antiproliferative activity in other systems is mediated via cellto-cell contact (36). The transfer of interferon-induced antiviral activity by a variety of cell types was not mediated by soluble factors released by these cells (37). The effect appears to require some type of as yet undefined attachment between the effector cell and the target cell (36); gentle agitation of a mixture of IFN-treated $L$ cells and Daudi cells prevented the transfer of the antiproliferative activity of the former cells (36).

IFNs are increasingly being considered as therapeutic agents for solid tumors and a variety of hematologic malignancies (38). The studies described here provide in vitro evidence that the antiproliferative effects of IFN may not be limited to intended abnormal cells but may extend to normal hematopoietic progenitors as well. Indeed, hematologic toxicity has been observed with interferon therapy, neutropenia being a commonly used reason for discontinuation of treatment (39, 40). It has been suggested that increased production of endogenous interferons may represent a pathogenic mechanism for the development of pancytopenia in some patients with aplastic anemia (14-16). A number of studies have demonstrated the presence in some patients with aplastic anemia of $\mathrm{T}$ lymphocytes capable of inhibiting the orderly proliferation and/or differentiation activities of autologous and heterologous hematopoietic progenitors in vitro $(17,33)$. In view of the findings presented here, the demonstration of increased levels of IFN in bone marrow of a majority of patients with aplastic anemia $(15,16)$, and the observation that the addition of antiinterferon antibody to bone marrow of aplastic anemia patients in vitro results in marked increase in hematopoietic colony formation $(15,16)$, the possibility is raised that the presence of $T$ cells with hematopoietic suppressor activity in these patients may be associated with IFN. Direct evidence in support of such an association has recently been described in a patient with diffuse well-differentiated lymphocytic lymphoma undergoing IFN therapy (17). Administration of IFN to this patient resulted in a severe pancytopenia characterized by reduced marrow CFU-E activity and increased numbers of marrow suppressor $\mathrm{T}$ cells $\left(\mathrm{OKT} 8^{+}\right.$cells). Immunosuppressive therapy resulted in marked improvement associated with a 
reduction in the numbers of $\mathrm{OKT}^{+} \mathrm{T}$ cells (17). Whether IFN therapy was responsible for the increase in suppressor $T$ cells is not known.

Our results also show that significant suppression of erythropoiesis occurred in the presence of relatively larger concentrations of $\gamma$-IFN than has been previously reported (12). It is likely that differences in experimental procedure and design played a significant role in bringing about these differences. In this regard, Broxmeyer et al. (12) employed an external source of BPA in their cultures that may have recruited a more immature population of BFU-E than those observed in our studies. Such cells may exhibit a different pattern of response to $\gamma$-IFN. It is also possible that the erythroid progenitors may exhibit a greater sensitivity to $\gamma$-IFN when cultured in methylcellulose (12) than plasma clot. Finally, the differences may be due to the different preparations of $\gamma$-IFN used. The natural $\gamma$-IFN used by Broxmeyer et al. (12) may be intrinsically more effective than the recombinant $\gamma$-IFN used in these studies.

\section{Acknowledgments}

This work was supported in part by the Veterans Administration and by grants AM-24027, AM-30914, and CA-23021 from the National Institutes of Health.

\section{References}

1. Preble, O. T., and R. M. Friedman. 1983. Biology of disease: interferon-induced alterations in cells: relevance to viral and nonviral diseases. Lab. Invest. 49:4-18.

2. Isaacs, A., and J. Lindenmann. 1957. Virus interference. I. The interferon. Proc. R. Soc. Lond. B Biol. Sci. 147:258-267.

3. Isaacs, A., J. Lindenmann, and R. C. Valentine. 1957. Virus interference. II. Some properties of interferon. Proc. R. Soc. Lond. B Biol. Sci. 147:268-273.

4. Friedman, R. M. 1977. Antiviral activity of interferon. Bacteriol. Rev. 41:543-567.

5. Ball, E. D., P. M. Guyer, L. Shen, J. M. Glynn, C. R. Maliszewski, P. E. Baker, and M. W. Fanger. 1984. Gamma interferon induces monocytoid differentiation in the HL-60 cell line. J. Clin. Invest. 73:1072-1077.

6. Gresser, I., D. Brouty-Boye, M. T. Thomas, and A. MacieiraCoelho. 1970. Interferon and cell division. I. Inhibition of the multiplication of mouse leukemia L1210 cells in vitro by interferon preparations. Proc. Natl. Acad. Sci. USA. 66:1052-1058.

7. Van't Hull, E., H. Schellekens, B. Lowenberg, and M. J. de Vries. 1978. Influence of interferon preparations on the proliferative capacity of human and mouse bone marrow cells in vitro. Cancer Res. 38:911-914.

8. Mannel, D. N., and W. Falk. 1983. Requirement of $\gamma$-interferon in activation of macrophages for tumor cytotoxicity. In Interleukins, Lymphokines, and Cytokines. J. J. Oppenheim, and S. Cohen, editors. Academic Press, Inc., New York. 287-290.

9. Vilcek, J., P. J. Pearlstein, L. E. Junming, D. S. Stone-Wolff, H. C. Kelker, and Y. K. Yip. 1983. Interferon-gamma: interactions with other lymphokines. In The Biology of the Interferon System. E. DeMaeyer, and H. Schellekens, editors. Elsevier Science Publishers, Amsterdam. 281-292.

10. Neumann, H. A., and A. A. Fauser. 1982. Effect of interferon on pluripotential hemopoietic progenitors (CFU-GEMM) derived from human bone marrow. Exp. Hematol. 10:587-590.

11. Verma, D. S., G. Spitzer, J. U. Gutterman, A. R. Zander, K. B. McCredie, and K. A. Dicke. 1979. Human leukocyte interferon preparation blocks granulopoietic differentiation. Blood. 54:1423-1427.
12. Broxmeyer, H. E., L. Lu, E. Platzer, C. Feit, L. Juliano, and B. Y. Rubin. 1983. Comparative analysis of the influences of human gamma, alpha, and beta interferons on human multipotential (CFUGEMM), erythroid (BFU-E) and granulocyte-macrophage (CFU-GM) progenitor cells. J. Immunol. 131:1300-1305.

13. Dukes, P. P., P. Izadi, J. A. Ortega, N. A. Shore, and E. Gomperts. 1980. Inhibitory effects of interferon on mouse megakaryocytic progenitor cells in culture. Exp. Hematol. 8:1048-1056.

14. Young, N., and P. Mortimer. 1984. Viruses and bone marrow failure. Blood. 63:729-737.

15. Zoumbos, N., J. Djeu, and N. Young. 1984. Interferon is the suppressor of hematopoiesis generated by stimulated lymphocytes in vitro. J. Immunol. 133:769-774.

16. Zoumbos, N., P. Gascon, J. Djeu, and N. Young. 1984. Interferon is present in normal human bone marrow and at high concentrations in patients with bone marrow failure. Clin. Res. 32: 307A. (Abstr.)

17. Mangan, K. F., B. Zidar, Z. Zeigler, A. Winkelstein, and R. K. Shadduck. 1984. Interferon induced aplasia: role of suppressor $T$ cells and recovery after treatment with horse anti-human thymocyte globulin (ATG). Clin. Res. 32:314A. (Abstr.)

18. Nathan, D. G., C. Chess, P. G. Hillman, B. Clark, J. Beard, F. Werler, and D. Housman. 1978. Human erythroid burst forming unit: T-cell requirement for proliferation in vitro. J. Exp. Med. 147:324339.

19. Zuckerman, K. S. 1981. Human erythroid burst forming units. Growth in vitro is dependent on monocytes, but not $\mathrm{T}$ lymphocytes. J. Clin. Invest. 67:702-708.

20. Gordon, L. I., W. J. Miller, R. F. Branda, E. D. Zanjani, and H. S. Jacob. 1980. Regulation of erythroid colony formation by bone marrow macrophages. Blood. 55:1047-1050.

21. Zanjani, E. D., P. B. McGlave, S. F. Davies, M. Banisadre, M. E. Kaplan, and G. A. Sarosi. 1982. In vitro suppression of erythropoiesis by bone marrow adherent cells from patients with fungal infection. Br. J. Haematol. 50:479-490.

22. Claeys, H., J. van Damme, M. De Ley, C. Vermlyen, and A. Billiau. 1982. Activation of natural cytotoxicity of human peripheral blood mononuclear cells by interferon: a kinetic study and comparison of different interferon types. Br. J. Haematol. 50:85-94.

23. Koff, W. C., I. J. Fidler, S. D. Showalter, M. K. Chakrabarty, B. Hampar, L. M. Ceccorulli, and E. S. Kleinerman. 1984. Human monocytes activated by immunomodulators in liposomes lyse herpesvirus-infected but not normal cells. Science (Wash. DC). 224:10071009.

24. Brunda, M. J., and D. Rosenbaum. 1984. Modulation of murine natural killer cell activity in vitro and in vivo by recombinant human interferons. Cancer Res. 44:597-601.

25. Dimitriu-Bona, A., G. R. Burmester, S. J. Waters, and R. J. Winchester. 1983. Human mononuclear phagocyte differentiation antigens. I. Patterns of antigenic expression on the surface of human monocytes and macrophages defined by monoclonal antibodies. $J$. Immunol. 130:145-152.

26. Todd, R. F., A. V. Agthoven, S. F. Schlossman, and C. Terhorst. 1982. Structural analysis of differentiation antigens Mol and Mo2 on human monocytes. Hybridoma. 1:329-337.

27. Todd, R. F., L. M. Nadler, and S. F. Schlossman. 1981. Antigens on human monocytes identified by monoclonal antibodies. J. Immunol. 126:1435-1442.

28. Kung, P. C., G. Goldstein, E. L. Reinherz, and S. F. Schlossman. 1979. Monoclonal antibodies defining distinctive human T-cell surface antigens. Science (Wash. DC). 206:347-349.

29. Koski, P. R., D. G. Poplac, and R. M. Blaese. 1976. A nonspecific esterase method for the identification of monocytes and macrophages. In In Vitro Methods in Cell Mediated and Tumor Immunity. B. R. Bloom, and J. R. David, editors. Academic Press, Inc., New York. 359. 
30. Smith, K. A., T. N. Fredrickson, L. E. Mobratten, and E. DeMaeyer. 1977. The interaction of erythropoietin with fetal liver cells. II. Inhibition of the erythropoietin effect by interferon. Exp. Hematol. 5:333-340.

31. Ortega, J. A., A. Ma, N. A. Shore, P. P. Dukes, and T. C. Merigan. 1979. Suppressive effect of interferon on erythroid cell proliferation. Exp. Hematol. 7:145-150.

32. Klinpel, G. R., W. R. Fleischmann, and K. D. Klinpel. 1982. Gamma interferon (IFN) and IFN $\alpha / \beta$ suppress murine myeloid colony formation (CFU-C): magnitude of suppression is dependent upon level of colony stimulating factor (CSF). J. Immunol. 129:76-80.

33. Hoffman, R., E. D. Zanjani, J. D. Lutton, R. Zalusky, and L. R. Wasserman. 1976. Suppression of erythroid colony formation by lymphocytes from patients with aplastic anemia. N. Engl. J. Med. 296:10-13.

34. Banisadre, M., R. C. Ash, J. L. Ascensao, N. E. Kay, and E. D. Zanjani. 1981. Suppression of erythropoiesis by mitogen activated T lymphocytes in vitro. In Experimental Hematology Today. S. J.
Baum, G. D. Ledney, and A. Khan, editors. S. Krager, New York. 151-159.

35. Fauser, A. A., and H. A. Messner. 1979. Identification of megakaryocytes, macrophages, and eosinophils in colonies of human bone marrow containing neutrophilic granulocytes and erythroblasts. Blood. 53:1023-1027.

36. Lloyed, R. E., J. E. Blalock, and G. J. Stanton. Cell-to-cell transfer of interferon-induced antiproliferative activity. Science (Wash. DC). 221:953-955.

37. Blalock, J. E. 1979. Cellular interactions determine the rate and degree of interferon action. Infect. Immun. 23:496-501.

38. Kirkwood, J. M., and M. S. Ernstoff. 1984. Interferons in the treatment of human cancer. J. Clin. Oncol. 2:336-352.

39. Irgimarsson, S., K. Cantell, and H. Strarder. 1979. Side effects of long term treatment with human leukocyte interferon. $J$. Infect. Dis. 140:560-563.

40. Priestman, T. J. 1980. Initial evaluation of human lymphoblastoid interferon in patients with advanced malignant disease. Lancet. II:113-118. 